\title{
Electrochemical injection of cathionic corrosion inhibitors
}

\author{
[ Milan Kouril, Tomas Lovasi, Sarka Msallamova, Jiri Nemecek, Rostislav Sulc ]
}

\begin{abstract}
Electrochemical chloride extraction from a reinforced concrete structure may be accompanied with an electrochemical injection of healing agents if such agents are positively charged and are able to migrate towards the activated reinforcement. Positive charge carrying nanoparticles or cathionic corrosion inhibitors might be the proper choice. Organic substances with a positive charge and their salts are mostly such inhibitors. The essential conditions for successful application of such corrosion inhibitors are their sufficient corrosion inhibition efficiency that was studied and evaluated elsewhere and their stability of positive charge in alkaline concrete environment and their migration ability through concrete pore system.
\end{abstract}

Keywords - corrosion, concrete, electrochemical injection

\section{Introduction}

Steel embedded in fresh concrete is largely in a passive state due to the formation of a thin layer of iron oxide on its surface. This passive layer is stable due to the high alkalinity of the concrete, the $\mathrm{pH}$ of which ranges from 12.5 to 13 [1]. In order for corrosive action to take place, this passive layer must be broken. This process is most often done in concrete in two ways. The first way is the penetration of chloride ions through the concrete cover layer up to the steel reinforcement. The chlorides may originate from seawater and de-icing salt but also in admixtures used in concrete production itself.

Milan Kouril

University of Chemistry and Technology, Prague

Czech Republic

\section{Tomas Lovasi}

University of Chemistry and Technology, Prague Czech Republic

Sarka Msallamova

University of Chemistry and Technology, Prague Czech Republic

Jiri Nemecek

Czech Technical University

Czech Republic

Rostislav Sulc

Czech Technical University

Czech Republic
Accelerated steel reinforcement corrosion in concrete is often observed in a chloride-containing environment, leading to premature failure of reinforced concrete structures and consequently shortened lifetime [2].The second possible way of accelerating steel corrosion in concrete is that the concrete is carbonated. Carbonation occurs as a result of the carbon dioxide reaction from the atmosphere with the concrete, which results in a reduction of the alkalinity of the concrete [3]. Carbonation of the concrete causes problems in practice (lowering the $\mathrm{pH}$ and lowering the basic protection provided by concrete) only when the concrete layer over the reinforcing steel is not sufficiently thick and the concrete is porous [4, 5]. Once the corrosion already starts, it can lead to complete damage to the structure. The corrosion process, as an electrochemical process, takes place on the surface of the steel where the anodic and cathodic regions are located in parallel $[6,7]$.

Chloride-induced corrosion can be mitigated by reducing the chloride ion level in concrete by various mechanisms. One of the possible examples is cathodic protection or cathodic prevention, but cathodic prevention is designed to protect steel in concrete even before the onset of chloride-induced corrosion [8]. Other options are thermal acceleration diffusion, removal of chlorides under pressure [9], re-alkalization and electrochemical extraction [10,11]. The difference between cathodic prevention and cathodic protection rests in the used current density and steel protection method. Both methods are introduced for a longer period. Cathodic prevention, which is designed to protect steel in concrete even before corrosion, uses low current densities ranging from 0.5 to $2 \mathrm{~mA} / \mathrm{m}^{2}$. While cathodic protection is aimed at reducing corrosion rate in construction where the chloride process is already under way, it is now necessary to use higher current densities of up to $15 \mathrm{~mA} / \mathrm{m}^{2}$ or $20 \mathrm{~mA} / \mathrm{m}^{2}[12,13]$. Electrochemical extraction of chlorides uses an electric field with a current density in the range of $1-5 \mathrm{~A} / \mathrm{m}^{2}$. Such an electric field is introduced into specific components of the structure to undergo rehabilitation, with the migration of chloride ions from the concrete for several weeks $[14,15]$. The foregoing method may be supplemented by the electrochemical injection of the corrosion inhibitor (EICI).

The arrangement EICI is similar to the electrochemical extraction of chlorides, so that the electric field flows between the steel as the cathode and the outer anode, the whole arrangement being inserted into the electrolyte which adheres to the structure surface [16]. The effects of chloride-induced corrosion can also be mitigated by the use of some chemicals that serve as corrosion inhibitors. Under the action of the electric field, the cationic component of the corrosion inhibitor migrates through the concrete layer to the cathode while the chloride ions in the concrete migrate from the concrete to the anode [17]. At the same time, the alkalinity of the pore 
Proc. of the Sixth International Conference on Advances in Civil, Structural and Environmental Engineering - ACSEE 2017. Copyright ( $\odot$ Institute of Research Engineers and Doctors. All rights reserved.

ISBN: 978-1-63248-139-9 doi: 10.15224/ 978-1-63248-139-9-27

solution is increased in the vicinity of the steel reinforcement. This phenomenon has the effect of promoting repassivation of steel. It has been shown that electrochemical injection is an effective way of adding corrosion inhibitors to already existing structures and can be used as a rehabilitation measure to slow down or reduce corrosion. The study showed that injection could provide adequate protection against the corrosion of steel reinforcements in chloride contaminated concrete [18]. This technology is new and has a non-destructive nature requiring only a temporary installation (10-15 days). According to the National Association of Corrosion Engineers (NACE), the current density used should not exceed $4 \mathrm{~A} / \mathrm{m}^{2}$ of steel surface and the charge used during the treatment should not exceed $1500 \mathrm{Ah} / \mathrm{m}^{2}$ [18].

Such inhibitors may be surface-applied and used to rehabilitate existing structures $[3,18]$ or pass into hardened concrete through an external electrical mesh. However, the mitigating mechanism involves a complex electrochemical process that depends primarily on the concentration of chloride ions relative to the concentrations of corrosion inhibitors [4]. The efficiency of a corrosion inhibitor in mitigating chloride-induced corrosion can be simplistically determined by laboratory tests in a simulated pore solution containing concurrently the inhibitor and chloride ions at a given concentration while simultaneously investigating the corrosion rate over time. Prediction of inhibitor and chloride ion concentrations on the steel surface in concrete after application of the electric field requires extensive modelling research.

A corrosion inhibitor suitable for electrochemical injection should fulfill several conditions, e.g. to provide sufficient protection against corrosion in the chloride ion environment and to exist predominantly in a cationic form in an aqueous medium under the given conditions. Therefore, corrosion inhibitors based on amine or alkanolamine are a good choice when stable in its cathionic form under given conditions with respect to concrete pore solution $\mathrm{pH}$. Such a type of corrosion inhibitor is dependent on the $\mathrm{pH}$ of the solution and the dissociation constant $\left(\mathrm{K}_{\mathrm{a}}\right)$ of their conjugate acids when dissolved in aqueous solutions as shown in the equations.

As mentioned above, a properly chosen inhibitor may affect the on-going process on the reinforcing steel surface. There are many inhibitors tested in the literature, which individual authors undergo in a variety of tests. Highly investigated inhibitors are organic amines and alkanolamines (AMA) inhibitors and their salts with organic and inorganic acids or aminoalcohols. Some studies $[11,12]$ state that AMA and associated radicals form a layer on the surface of steel that completely covers all anodic and cathodic components and therefore are mixed type inhibitors. In another literature $[13,19]$, further studies (with potentiodynamic polarization) indicate that amine-based inhibitors and alkanolamines act mainly on anodic activity, with the consequent increase in corrosion potential. Another inhibitor already added to said inhibitor is guanidine carbonate $\left(\mathrm{C}_{2} \mathrm{H}_{10} \mathrm{~N}_{6} \cdot \mathrm{CH}_{2} \mathrm{O}_{3}\right)$. Guanidine carbonate was tested together with ethanolamine in [20]. Both of these inhibitors were introduced into saturated samples of carbonated and non-carbonated concrete. The efficiency of injection of both inhibitors (ethanolamine and guanidine) under the applied electric field was found to be much higher in carbonated concrete than in non-carbonated concrete.

The aim of this study was to investigate the corrosion inhibition efficiency of several corrosion inhibitors with prospectively cathionic action in alkaline concrete environment and to prove their migrating ability in concrete.

\section{Experimental}

\section{A. Corrosion inhibition efficiency}

Corrosion inhibition efficiency of three prospective cathionic corrosion inhibitors was evaluated by means of polarization resistance of carbon steel in simulated concrete pore solution. For fresh concrete pore solution, a saturated calcium hydroxide solution was used with addition of sodium hydroxide for adjusting the $\mathrm{pH}$ value to 13.0. Carbonated concrete pore solution was simulated by water in equilibrium with solid calcium carbonate. Sodium chloride has been dissolved in both the simulated concrete pore solutions in various amount in order obtain chloride concentration of 0.1 ; $0.3 ; 1.0 ; 3.0 ; 10.0$ or $15.0 \mathrm{~g} / \mathrm{L}$. The inhibitor molar concentration should equal the concentration of chloride ions in the $15.0 \mathrm{~g} / \mathrm{L}$ solution. Thus, the inhibitor concentration of $0.423 \mathrm{~mol} / \mathrm{L}$ was used in the case of all the three involved inhibitors. Guanidine carbonate (99\%), tetrabutylammonium bromide (99\%) and tetrabutylphosphonium bromide (98\%) in in proper amount were dissolved in the simulated pore solutions.

The CSN 11321 carbon steel (0.045 wt.\% of carbon, 0.382 wt. \% of manganese, 0.007 wt. $\%$ of phosphorous, 0.009 wt. $\%$ of sulphur) was exposed in the simulated pore solutions for 24 hours. The carbon steel flat specimens were cleaned by grinding (P320) and rinsed with ethanol prior to exposure. The specimens were fixed to the corrosion cell equipped with a counter (platinum) and a reference electrode (saturated calomel). The specimen served as the cell's bottom. The exposed area $\left(2.54 \mathrm{~cm}^{2}\right)$, defined by a gasket, was overlaid with $40 \mathrm{~mm}$ thick layer of the electrolyte. The linear polarization measurements were performed after 24 hours of the free corrosion potential stabilization within the potential interval -10 up to $+10 \mathrm{mV}$ with respect to free corrosion potential using the scan rate of $0.1 \mathrm{mV} / \mathrm{s}$. Polarization resistance was determined as the slope of the tangent to the recorded curve at the point of original stabilized free corrosion potential. The polarization resistance is inversely proportional to corrosion rate. Five specimens were exposed in parallel.

\section{B. Electrochemical injection}

Galvanostatic mode was used for electrochemical injection of the cathionic corrosion inhibitors into a concrete specimen. Following components were used for mixing $1 \mathrm{~m}^{3}$ of concrete: $262 \mathrm{~kg}$ of cement grade CEM I 42.5R, $210 \mathrm{~kg}$ of water, $1150 \mathrm{~kg}$ of sand $(0-4 \mathrm{~mm}), 582 \mathrm{~kg}$ of aggregate $(8-16 \mathrm{~mm})$ and $291 \mathrm{~kg}$ of aggregate (4-8 mm). Water-to-cement ratio corresponded to 0.8 . Poor quality of concrete has been chosen on purpose for accelerating the transport processes. The concrete cylinder (100 $\mathrm{mm}$ in diameter, $50 \mathrm{~mm}$ high) saturated 
with water was fixed in between two chambers (app. $0.5 \mathrm{~L}$ ) for anolyte and catholyte (Fig. 1). Stainless steel (AISI 316) mesh electrodes were built in the chambers parallel to the both flat surfaces of the concrete cylinder at the distance app. $3 \mathrm{~mm}$. The unexposed surface of concrete specimen was painted by a synthetic paint IZOBAN (Detecha). The catholyte chamber was filled with $3 \% \mathrm{NaCl}$ solution. The anolyte chamber was filled with an inhibitor solution the concentration of which was $0.423 \mathrm{~mol} / \mathrm{L}$. Constant current $2.53 \mathrm{~mA}$ or $12.65 \mathrm{~mA}$ was applied between the stainless steel mesh electrodes and through the concrete specimen. The current level corresponds to current density of $1 \mathrm{~A} / \mathrm{m}^{2}$ or $5 \mathrm{~A} / \mathrm{m}^{2}$ respectively. The surface area of the mesh electrodes was taken into account. The current was introduced by Radelkis $\mathrm{OH}-404 / \mathrm{A}$ for 7 day or 14 days, respectively.

After the exposure - injection, three 5 millimeters thick slices were taken from the catholyte $(\mathrm{NaCl}$ solution) side and two 5 millimeters thick slices were taken from the anolyte (inhibitor solution) side in order to determine the concentration profile of the injected inhibitor across the concrete cylinder. The slices were pulverized using a laboratory mill and the powder was dried at $80{ }^{\circ} \mathrm{C}$ overnight. The amount of 20 grams of the powder was then mixed with $50 \mathrm{ml}$ of distilled water and the mixture was ultrasonicated for 1 hour. The liquid phase was separated from the solid by means of centrifugation and analyzed. The guanidine concentration was determined by a mass spectrometer LC-MS LTQ-Orbitrap Velos. The chloride concentration was determined by an absorption spectrophotometer FIA lab 2000.

The concentration profile obtained by electrochemical injection was compared with that resulting from a plain diffusion. The diffusion experiment was set exactly in the same way as the electrochemical injection, except the current that was not introduced.

Up to now, the migration test has been performed for guanidine. The results for the other corrosion inhibitors will be published elsewhere.

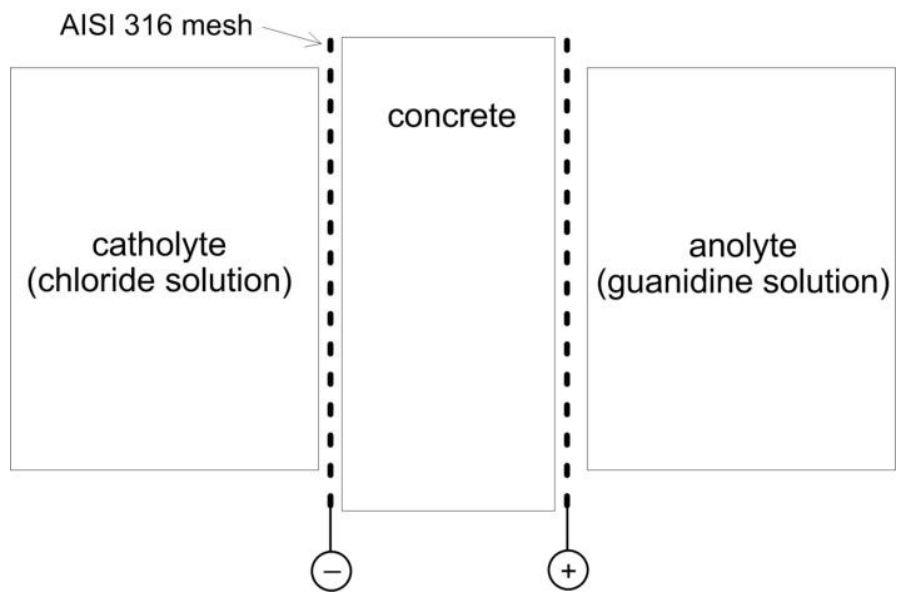

FIGURE 1 EXPERIMENTAL DESIGN OF ELECTROCHEMICAL INJECTION

\section{Results and discussion}

\section{A. Corrosion inhibition efficiency}

Carbon steel in fresh concrete pore solution showed extremely high values of polarization resistance (Fig. 2) approaching $100 \mathrm{ohms} . \mathrm{m}^{2}$. Such a magnitude of polarization resistance corresponds to negligible corrosion rate resulting from spontaneous passivation of steel in fresh concrete chloride free environment. Addition of chlorides $(15 \mathrm{~g} / \mathrm{L})$ into the pore solution resulted in a drop of polarization resistance (an increase of corrosion rate) by two orders of magnitude as a due to depassivation of steel and transfer to active corrosion. It was believed that an addition of an equimolar (with respect to chloride concentration) amount of an inhibitor would reestablish passivity of steel and low corrosion rate. As shown on Fig. 2, the polarization resistance values increased to the region of units of ohms. $\mathrm{m}^{2}$, however the values of chloride free environment were not approached by far. The inhibition efficiency of the selected inhibitors under consideration is thus questioned.

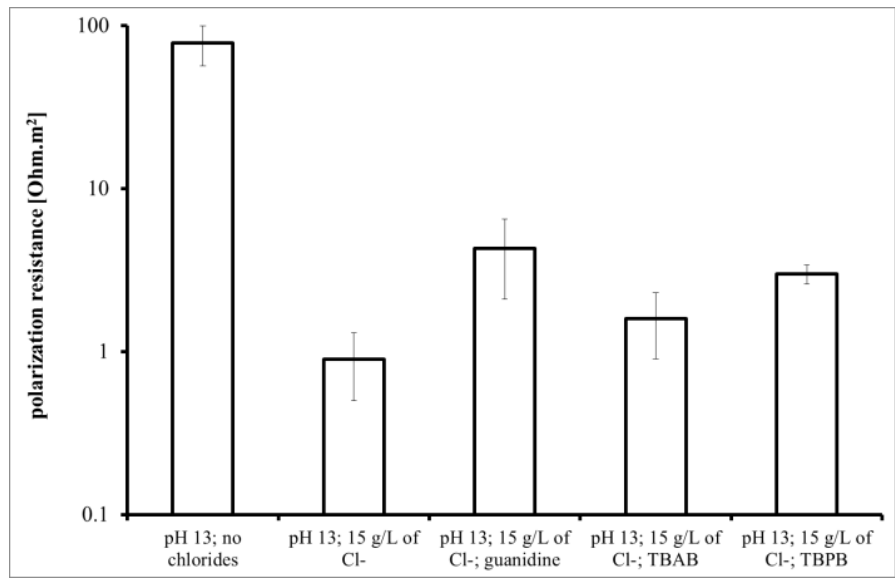

FIGURE 2 POLARIZATION RESISTANCE OF STEEL IN FRESH CONCRETE PORE SOLUTION WITH OR WITHOUT CHLORIDES AND GUANIDINE

Carbonation had the same effect in terms of depassivation as an increase of chloride concentration in fresh concrete pore solution. At lower $\mathrm{pH}$, the polarization resistance dropped down to the order of units of ohm. $\mathrm{m}^{2}$, even if no chlorides were present (Fig. 3). Addition of guanidine resulted in significant improvement of corrosion resistance back to the order of tens of ohm. $\mathrm{m}^{2}$. Guanidine thus showed its inhibition efficiency in carbonated concrete pore solution.

Consequently, a tolerance of such an inhibited system to chlorides was tested. The results of polarization resistance show (Fig. 3) that the polarization resistance decreased progressively as chloride concentration in carbonated concrete pore solution increased, nevertheless the $\mathrm{R}_{\mathrm{p}}$ values remained in the order of tens of ohm. $\mathrm{m}^{2}$ even at $1 \mathrm{~g} / \mathrm{L}$ of chlorides. Thus, guanidine showed promising inhibitive action in carbonated concrete and in concrete pore solution environment with chloride content below app. $1 \mathrm{~g} / \mathrm{L}$. 
What remains unanswered is whether the transport of such a corrosion inhibitor might be accelerated by electrochemical injection to chloride contaminated and/or carbonated concrete while extracting chlorides and/or realkalizing the concrete surrounding the depassivated steel.

\section{B. Electrochemical injection}

The chloride extraction process can be clearly seen in Fig. 4 and Fig. 5 that represents a scheme of the concrete cylinder split into slices that were submitted to chloride and quinidine analysis. The particular concentration of guanidine or chlorides is displayed in the Fig. 4 and Fig. 5, respectively.

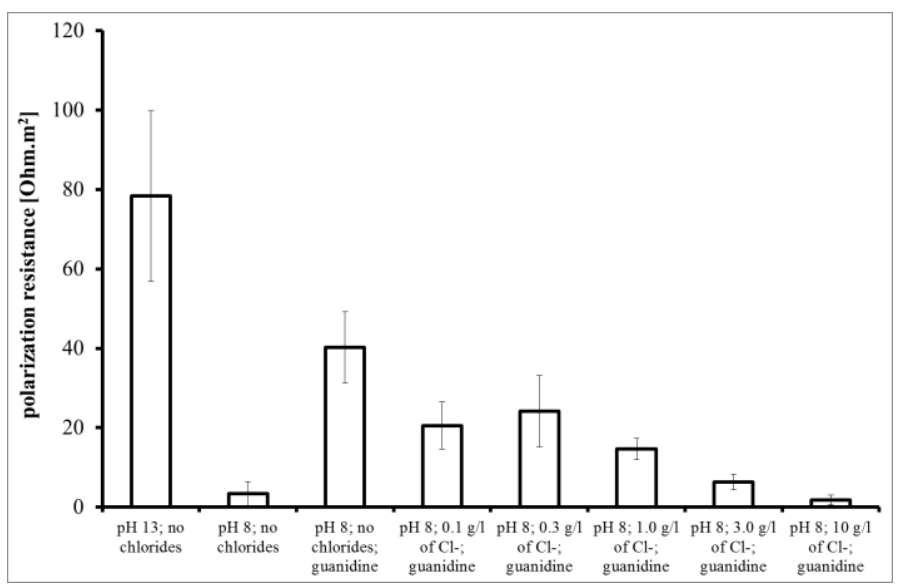

FIGURE 3 POLARIZATION RESISTANCE OF STEEL IN CARBONATED CONCRETE PORE SOLUTION WITH OR WITHOUT CHLORIDES AND GUANIDINE

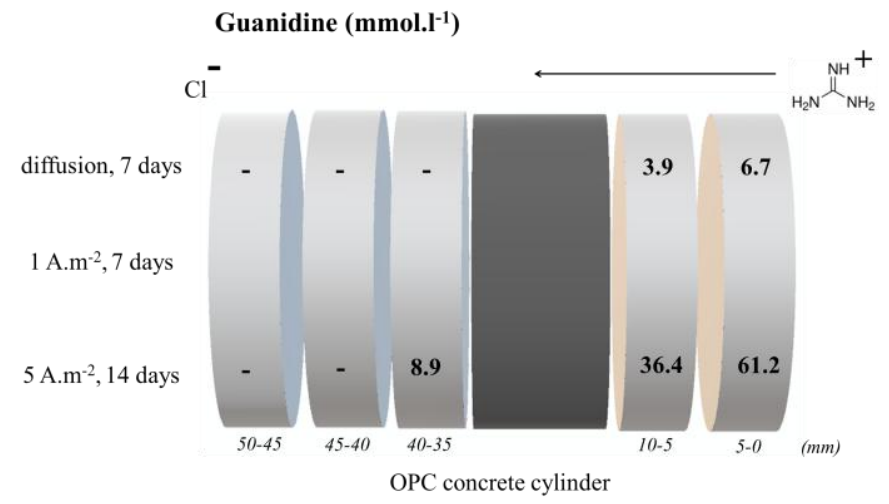

FIGURE 4 CONCENTRATION PROFILE OF GUANIDINE IN CONCRETE CYLINDER SPECIMEN

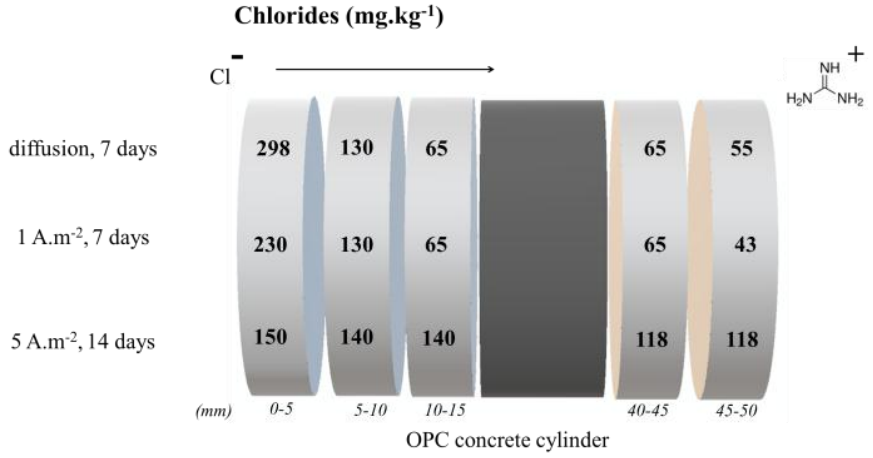

FIGURE 5 CONCENTRATION PROFILE OF CHLORIDES IN CONCRETE CYLINDER SPECIMEN

Fig. 4 shows that the guanidine inhibitor reached the second concrete section in a detectable amount by diffusion within 7 days. Guanidine was brought demonstrably by diffusion to the depth of $10 \mathrm{~mm}$ in the poor quality concrete within a week at laboratory temperature. Acceleration of the transport by migration when applying the current density of $5 \mathrm{~A} / \mathrm{m}^{2}$ resulted in ten times higher content of the inhibitor inside the first two concrete sections. The inhibitor was also identified in the section $35-40 \mathrm{~mm}$ distant from the concrete surface that acted as the entrance for the inhibitor. The results proved that guanidine is transportable by migration in fresh concrete. Its cathionic form is probably stable in poor quality fresh concrete and electrochemical injection is applicable for accelerating its transport to a depth of several tens of millimeters in concrete.

The results of the inhibitor distribution for $1 \mathrm{~A} / \mathrm{m}^{2}$ migration test were not available at the time of finishing the paper. However, insignificant action of migration is expected in that case as no migration contribution was observed for chlorides. The chlorides were transported from the catholyte either by diffusion or by contribution of migration and no chloride distribution difference between plain diffusion and $1 \mathrm{~A} / \mathrm{m}^{2}$ migration acceleration was observed (Fig. 5). After the $5 \mathrm{~A} / \mathrm{m}^{2}$ migration test, the distribution of chlorides was almost uniform across the concrete cylinder while the first section facing the catholyte contained lower amount of chlorides compared to diffusion or $1 \mathrm{~A} / \mathrm{m}^{2}$ migration test. That revealed fast extraction of chlorides from the catholyte. Chloride ions were driven through the concrete cylinder to anolyte where an elevated concentration of chlorides induced severe corrosion of the stainless steel anode.

\section{Conclusions}

Guanidine ion proved its migration ability even in alkaline pore concrete solution. Guanidine of detectable concentration reached a depth $40 \mathrm{~mm}$ in concrete by migration $\left(5 \mathrm{~A} / \mathrm{m}^{2}, 14\right.$ days) and only $10 \mathrm{~mm}$ by diffusion (7 days) in given experimental arrangement. Guanidine carbonate solution is applicable as a source guanidine cathions with simultaneous electrochemical chloride extraction. Transport of guanidine towards steel reinforcement can be accelerated in this way. 
On the other hand, the corrosion inhibition efficiency is questionable. None of the tested inhibitors (guanidine carbonate, tetrabutylammonium bromide and tetrabutylphosphonium bromide) provided sufficient inhibiting effect in highly chloride contaminated fresh concrete pore solution. Inhibition efficiency at lower chloride content is to be investigated and critical chloride content for acceptable inhibition effect should be found. Such a critical chloride content has been identified for carbonated concrete pore solution to be app. $1 \mathrm{~g} / \mathrm{L}$.

\section{References}

[1] M Pandiarajan et al., "Corrosion inhibitors for concrete corrosion - an overview" Eur. Chem. Bull.,vol. 2, pp. 1-8, 2013.

[2] G. Batis, A. Routoulas and E. Rakanta, "Effects of migrating inhibitors on corrosion of reinforcing steel covered with repair mortar" Cement and Concrete Composites, vol. 25, pp. 109-115, 2003.

[3] J. M. Gaidis, "Chemistry of corrosion inhibitors" Cement and Concrete Composites, vol. 26, pp. 181-189, 2004.

[4] U. Angst et al., "Critical chloride content in reinforced concrete - A review" Cement and Concrete Research, vol. 39, pp. 1122-1138, 2009.

[5] P. Banfill, "Re-alkalization of carbonated concrete - effect on concrete properties" Construction and Building Materials, vol. 11, pp. 255-258, 1997

[6] J. Kubo et al., "Application of electrochemical organic corrosion inhibitor injection to a carbonated reinforced concrete railway viaduct" Construction and Building Materials, vol. 39, pp. 2-8, 2013.

[7] J. García et al., "Effect of cathodic protection on steel-concrete bond strength using ion migration measurements" Cement and Concrete Composites, vol. 34, pp. 242-247, 2012.

[8] J. M. Miranda et al., "Several questions about electrochemical rehabilitation methods for reinforced concrete structures" Corrosion Science, vol. 48, pp. 2172-2188, 2006.

[9] P. Pedeferri, "Cathodic protection and cathodic prevention" Construction and Building Materials, vol. 10, pp. 391-402, 1996.

[10] A. S. Abdulrahman, L. Mohammad, S. H. Mohammad, "Corrosion inhibitors for steel reinforcement in concrete: A review". Scientific Research and Essays, vol. 6, pp. 4152-4162, 2011.

[11] G. K. Glass, A. M. Hassanein, N. R. Buenfeld, "Cathodic protection afforded by an intermittent current applied to reinforced concrete" Corrosion Science, vol. 43, pp. 1111-1131, 2001.

[12] S. P. Karthick et al., "Electrochemical process to improve the durability of concrete structures" Journal of Building Engineering, vol. 7, pp. 273280, 2016.

[13] N. M. Ihekwaba, B. B. Hope, C. M. Hansson, "Structural shape effect on rehabilitation of vertical concrete structures by ECE technique" Construction and Building Materials, vol. 26, pp. 165-175, 1996.

[14] U. A. Birnin-Yauri, F. P. Glasser, "Friedel's salt, $\mathrm{Ca}_{2} \mathrm{Al}(\mathrm{OH})_{6}(\mathrm{Cl}, \mathrm{OH}) \cdot 2 \mathrm{H}_{2} \mathrm{O}$ : its solid solutions and their role in chloride binding" Cement and Concrete Research, vol. 28, pp. 1713-1723, 1998.

[15] S. Msallamova et al., "The differential aeration cell and the corrosion paradox" Materials and corrosion-Werkstoffe und Korrosion, vol. 66, pp. 498-503, 2015.

[16] J. C. Orellan, J. C. Escadeillas, G. Arliguie, "Electrochemical chloride extraction: efficiency and side effects" Cement and Concrete Research, vol. 34, pp. 227-234, 2004.

[17] C. Xu et al., "Organic corrosion inhibitor of triethylenetetramine into chloride contamination concrete by electro-injection method" Construction and Building Materials, vol. 115, pp. 602-617, 2016.

[18] J. Carmona, P. Garcés, M. A. Climent, "Efficiency of a conductive cement-based anodic system for the application of cathodic protection, cathodic prevention and electrochemical chloride extraction to control corrosion in reinforced concrete structures" Corrosion Science, vol. 96, pp. 102-111, 2015.
[19] S. Sawada et al., "Electrochemical injection of organic corrosion inhibitors into carbonated cementitious materials: Part 1. Effects on pore solution chemistry" Corrosion Science, vol. 49, pp. 1186-1204, 2007.

About Author (s):

Guanidine carbonate solution is applicable as a corrosion inhibitor by means of electrochemical injection with simultaneous electrochemical chloride extraction. 